obeys not only a certain periodic law, as expressed by the general formula, but is also linked up with the general geological structure of the region and is therefore related to the geological history of the sedimentary complex. The coefficient of periodicity ( $\omega)$ appears to be especially significant, and the isopleth maps of this coefficient can be easily correlated with either the structural maps or the isopachyte maps. According to whether the members of the equation contain the minimum, maximum or intermediate value of $\omega$, they are called micro-, macroor meso-rhythms.

To Vistelius all this suggests that porosity is closely related to the processes of deposition and epigenesis (cementation and leaching), and so can be used as a measure of what he calls the "phase differentiation' of the sedimentary complex, the phases in this case being the solid phase (mineral components of rocks) and the liquid and gaseous phases (infilling the pore space). If the empirical equation of the vertical distribution of porosity is compared with the equation expressing the normal law of errors, or rather the function of distributed probabilities, one is able to get an estimate of the magnitude of the secondary processes (epigenesis) as compared with the magnitude of the primary processes (sedimentation). This is achieved by the construction of isopleth maps for kurtosis and skewness, which provide a sensitive method of discovering the distribution of 'fossilized processes'.

All this work is still in its pioneering stage and as presented can be appreciated only by geologists well versed in modern statistical methods. It is rather difficult to evaluate the significance of isopleth maps for equation coefficients when these are compared with structural contour maps (isohyps or isopachytes). In spite of this difficulty, this work appears very interesting and important. There is a suggestion that this method may have a wider applicability to geological problems in which the immediate data do not allow any direct correlation or deduction. The practical importance of the application of statistical methods to geology may be considerable. In the case discussed by Vistelius, the porosity of the rocks has a direct bearing on the distribution of reservoir beds in an oilfield, but it is not difficult to find many other instances of work of economic value in which statistical methods may have an application. Such are, for example, water supplies, distribution and grade of coal in coalfields, and other similar problems.

S. I. TOMKEIEFF

\section{ELEMENTARY PARTICLES AND THE GEOMAGNETIC FIELD}

$\mathrm{R}$ ECENTLY J. Barnóthy ${ }^{1}$ has proposed an explanation of the elementary particles (protons, electrons, etc.) in terms of serial universes, each enclosed in one of higher order. The elementary particles of our universe are universes of a lower order; our universe is an elementary particle in a higher universe. The universes are three-dimensional curved ones enclosed in a four-dimensional space; that of an elementary particle has a two-dimensional intersection with our universe, which delimits a region excluded from the latter. Mass in an elementary universe becomes imaginary mass $(\sqrt{-1} \times$ mass) when viewed from ours; the gravitational attraction between two imaginary masses is a real electrostatic force. The spin of an elementary universe gives parts of its mass a velocity greater than $c$; this makes the imaginary mass acquire real linear and angular momentum. Nuclear forces in our universe are the counterparts of cosmical repulsions in the elementary universe. Protons and electrons arise from Einstein universes of negative and positive curvature ; a neutron is formed by the combination of a proton and another particle arising from a de Sitter universe.

Barnóthy expresses these general ideas in a quantitative form. Like Eddington, by some of whose ideas he has been profoundly influenced, he derives an impressive list of theoretical values of fundamental constants, in good agreement with the experimental values. One must add that, again as with Eddington, it is often difficult to trace the interconnexions between different parts of his argument. In particular, the mechanism by which internal properties of a micro-universe react on our universe is far from clear.

Barnothy claims to explain the proportionality between magnetic moment and angular momentum of sun and earth, to which Blackett and Babcock have recently directed attention. [Barnóthy's work was not suggested by that of Blackett and Babcock; a preliminary account of his ideas, dated September 13, 1946, was received by Nature last year, but was not regarded as sufficiently explicit to warrant publication. EDIToRs.] He asserts that protons and neutrons possess, besides their real mass, an imaginary mass 643 times the electron-mass, and this imaginary mass behaves like an electric charge. The rotation of such a charge would produce terrestrial and solar magnetic fields of just the observed order of magnitude; but the suggestion is not at present satisfactory, since such a charge would produce a formidable electrostatic field, and Barnóthy declines to consider this field for the present.

T. G. Cowling

${ }^{1}$ Hungarian Institute for Meteor. and Terr. Mag., Papers on Terrestrial Magnetism, No. 2 (1947).

\section{FORTHCOMING EVENTS}

\author{
(Meetings marked with an asterisk * are open to the public)
}

\section{Monday, December 15}

Royal Physioal Soctety of EdInBdrgh (at the Royal Scottish Geographical Society, Synod Hall, Castle Terrace, Edinburgh), at 5.15 p.m.- Symposium on "The Species Concept".

MANChESTER IITERARY AND PHILOSOPHICAL SOCLETY (in the Reynolds Hall, College of Technology, Manchester), at 5.30 p.m. Prof. T. B. L. Webster: "Three Interpretations of Greek Vases" (Presidential Address).*

INSTITUTION OF THE RUBBER INDUSTRY, MANCHESTER AND DISTRICT SECTION (joint meeting with the SOCLETY OF CHEMICAL INDUSTRY, at the Engineers' "Club, Albert Square, Manchester), at 6.15 p.m.-Dr. ROYAL INSTITUTE OF CHEMISTRY, LONDON AND SOUTH-EASTERN CounTIEs SkCTION (at Norwood Technical Institute, Knight's Hill, London, S.E.27), at 7 p.m.-Microchemical Exhibition and Demonstration (organised by Mr. J. T. Stock).

\section{Tuesday, December 16}

ROYAL SOCIETY OF ARTS, DOMINIONS AND COLONIRS SECTION (at John Adam Street, Adelphi, London, W.C.2), at 2.30 p.m.-Mr. Colin Colahan: "Australian Art".

ROYAL ANTrRopologidar INSTITUTE (at 21 Bedford Square, London, W.C.1), at 5 p.m.-Dr. F. Hepner : "Communications and History". EdGenios Socretr (at the Royal Society, Burlington House, Piccadilly, London, W.1), at 5.30 p.m.-Dr. J. A. Fraser Roberts and Dr. Eliot Slater: "Genetics, Medicine and Practical Eugenics"."

Instrtution of Crvil EnginesRs (at Great George Street, London, S.W.1) at 5.30 p.m. - Sir Charles Inglis, F.R.S.: "Mathematics in S.W.1) at special Reference to a Recent Paper by the Lecturer on Shear Stress Determination".

SOCIRTY OF CHEMTCAL INDUSTRY, CHEMIOAL ENGINERRING GROUP (at the Geological Society, Burlington House, Piccadilly, London, W.1), at 5.30 p.m.-Mr. J.' G. Window: "Glass Equipment in the Chemical Engineering Industries". 